\title{
In-patient treatment of opiate dependence: medium-term follow-up outcomes
}

\author{
BOBBY P. SMYTH, JOE BARRY, ALISON LANE, MARY COTTER, MARY O'NEILL, \\ CAROLINE QUINN and EAMON KEENAN
}

\begin{abstract}
Background The outcome for opiatedependent patients seeking abstinence is unclear in this era of improved access to methadone maintenance.
\end{abstract}

\begin{abstract}
Aims To measure the outcome 2-3 years after in-patient treatment.
\end{abstract}

\begin{abstract}
Method Opiate-dependent patients admitted with a goal of abstinence were followed-up. A structured interview examined drug use and treatment in the preceding month.
\end{abstract}

Results Five patients had died and 109 (76\%) of the remaining 144 were interviewed. Fifty per cent (54 patients) reported recent opiate misuse and 57\% (62) were on methadone maintenance. Twenty-three per cent (25 patients) were abstinent (i.e. neither using opiates nor on methadone maintenance). Abstinence was significantly associated with completion of the 6 -week in-patient treatment programme and attendance at out-patient after-care, and negatively associated with a family history of substance misuse.

\section{Conclusions Abstinence remains an attainable goal. As the principal influence on outcome was treatment adherence, in- patient services should seek to enhance rates of programme completion. After- care should be provided to patients.We caution against use of pre-treatment patient characteristics as criteria for prioritising access to in-patient treatment.}

Declaration of interest None.
Large multicentre studies, such as the National Treatment Outcome Research Study (NTORS) in the UK and the Drug Abuse Treatment Outcome Study (DATOS) in the USA, have shown that in-patient treatment reduces mean levels of opiate use (Hubbard et al, 1997; Gossop et al, 1999). These studies, which examined heterogeneous populations, are limited because they cannot provide prognostic information on achievement of defined goals in the treatment of specific addiction disorders. While pre-treatment patient characteristics are poor predictors of treatment outcome, patients who spend a longer time in treatment have better outcomes (van de Velde et al, 1998; Gossop et al, 1999; Chutuape et al, 2001; Ghodse et al, 2002). We hypothesised that a substantial minority of patients would have attained abstinence when followed-up after inpatient treatment. Second, we hypothesised that treatment adherence characteristics predict abstinence.

\section{METHOD}

\section{Setting}

There has been substantial heroin misuse in Dublin since the 1970s. In the early 1990s addiction treatment services expanded substantially, moving away from an abstinence model and towards a harm reduction model (Farrell et al, 1999). Many small treatment clinics were opened in communities where opiate misuse was prevalent. General practitioners were recruited and trained to provide treatment for opiate misuse, offering both methadone maintenance and methadone reduction (Butler, 2002). Heroin misuse accounts for the vast majority of presentations to addiction services in Dublin (Smyth et al, 2000).

Cuan Dara opened in 1995, operating as a specialist in-patient drug dependency unit focusing primarily on detoxification. Prior to admission, all patients were expected to have commenced therapeutic work with an addiction counsellor in a community-based treatment service. In addition, all patients underwent a psychiatric assessment to determine psychiatric comorbidity and motivation to detoxify. The standard treatment programme lasted 6 weeks. This included a 10-day methadone detoxification and a benzodiazepine detoxification if indicated. Throughout treatment patients were involved in individual therapy and group therapy. This 6-week admission period is longer than in NTORS (Gossop et al, 1998). Patients were encouraged to access one of two forms of after-care following discharge. They could re-attend their local addiction counsellor or they could access an after-care programme in Cuan Dara one evening each week.

\section{Patients}

Consecutive admissions to the unit from July 1995 to December 1996 were included if they met the following criteria: primary diagnosis was opiate dependence syndrome, using ICD-10 criteria (World Health Organization, 1992) and they were admitted with the goal of ceasing use of all opiates, both illicit and prescribed. Baseline information was obtained from the semi-structured interview conducted by a psychiatrist on the day of their admission.

\section{Follow-up interview}

The core instrument used for data collection during follow-up was the Maudsley Addiction Profile (Marsden et al, 1998). This yields information on the 30 days prior to interview. Eight experienced addiction outreach workers conducted the interviews. Their expertise ensured that they had the skills and knowledge to locate patients both via treatment services and through drug users' peer networks. Followup interviews took place between July 1998 and March 1999. It was anticipated that the range in time gaps from discharge to follow-up interview would be wide. This was a consequence of the patients being admitted over an 18-month period and followed-up in an opportunistic manner over a 10-month period. Patients who agreed to participate were paid $\operatorname{Ir} £ 10$ $(€ 12.50)$. Following interview, those who described ongoing drug use problems were given advice and directed towards appropriate treatment services. 


\section{Statistical analysis}

The main outcome variable in this study was attainment of abstinence from opiates during the month prior to follow-up. Abstinence implied that patients were neither misusing opiates nor being prescribed methadone. The main predictor variables were those indicating treatment adherence: completion of detoxification; completion of the 6-week in-patient programme; and attendance at after-care for at least 6 months. We also explored the possibility that pre-treatment patient characteristics might predict abstinence at follow-up. Patients followed-up were compared with those lost to follow-up in order to rule out any systematic bias in the follow-up group.

Categorical variables were compared using Pearson's $\chi^{2}$ test or Fisher's exact test, as appropriate. Odds ratios (ORs) and their $95 \%$ confidence intervals $(95 \%$ CIs) are reported to indicate the direction and strength of associations. A multivariate analysis was conducted to identify variables that were independently associated with opiate abstinence. All variables were eligible for entry into the final regression equation. The selection method involved using both the forward and backward stepwise selection techniques, using the likelihood ratio test. The $P$ value for entry was set at 0.05 and that for removal at 0.10. Variables entered into the final regression equation were examined for evidence of interaction.

\section{RESULTS}

During the study period, 160 patients were admitted to Cuan Dara. All were opiatedependent. Eleven patients were admitted for stabilisation of their methadone maintenance treatment and were therefore excluded. The remaining 149 sought abstinence and were eligible to participate in the study. Males accounted for $67 \%$ and the median age was 23 years (interquartile range $(\mathrm{IQR})=20-28)$. Only $7 \%$ reported being in employment and $42 \%$ had been in prison. The median duration of opiate use was 4 years ( $\mathrm{IQR}=2-8)$. Injecting at some point in the person's lifetime was reported by $79 \%$. Sixty-one per cent were diagnosed as benzodiazepinedependent. Additional socio-demographic features, family history, previous addiction treatment, psychiatric history and substance misuse characteristics are provided in Table 1. Eighty-one per cent completed
Table I Baseline characteristics and treatment adherence among 149 opiate-dependent patients consecutively admitted to a specialist drug dependency unit in Dublin

\begin{tabular}{|c|c|c|}
\hline Characteristic & $n^{\prime}$ & $\%$ \\
\hline \multicolumn{3}{|l|}{ Socio-demographic and forensic history } \\
\hline \multicolumn{3}{|l|}{ Accommodation } \\
\hline Alone or with partner & 43 & 29 \\
\hline With parents & 90 & 60 \\
\hline With other relative & 7 & 5 \\
\hline Hostel or no fixed abode & 5 & 3 \\
\hline \multicolumn{3}{|l|}{ Sexual partner } \\
\hline No sexual partner & 56 & 38 \\
\hline Sexual partner using opiates & 41 & 28 \\
\hline Sexual partner not using opiates & 49 & 34 \\
\hline \multicolumn{3}{|l|}{ Education } \\
\hline Ceased education prior to age 15 years & 45 & 30 \\
\hline Remained in education until at least age 15 years & 103 & 70 \\
\hline \multicolumn{3}{|l|}{ Family history } \\
\hline History of substance misuse & 90 & 60 \\
\hline Parental alcohol misuse & 28 & 19 \\
\hline Parental opiate use & 8 & 5 \\
\hline Sibling alcohol misuse & 9 & 6 \\
\hline Sibling opiate use & 58 & 39 \\
\hline \multicolumn{3}{|l|}{ Past addiction treatment and psychiatric history } \\
\hline \multicolumn{3}{|l|}{ Number of previous attempted opiate detoxifications } \\
\hline None & 49 & 34 \\
\hline One & 41 & 28 \\
\hline Two or more & 55 & 38 \\
\hline Past (non-addiction) psychiatric history & 43 & 29 \\
\hline In-patient psychiatric treatment & 16 & II \\
\hline \multicolumn{3}{|l|}{ Substance misuse } \\
\hline \multicolumn{3}{|l|}{ Principal opiate of misuse } \\
\hline Heroin & $|3|$ & 89 \\
\hline Methadone & 10 & 7 \\
\hline Morphine sulphate & 2 & I \\
\hline Combination of opiates & 5 & 3 \\
\hline \multicolumn{3}{|l|}{ Quantity of heroin use (per day) } \\
\hline Less than I.5 'quarters' & 28 & 22 \\
\hline I.5-3.0 'quarters' & 59 & 47 \\
\hline More than 3.0 'quarters' & 40 & 31 \\
\hline \multicolumn{3}{|l|}{ Route of use of main drug } \\
\hline Chase (smoke) & 65 & 45 \\
\hline Inject & 71 & 49 \\
\hline Oral & 9 & 6 \\
\hline \multicolumn{3}{|l|}{ Adherence with in-patient treatment } \\
\hline \multicolumn{3}{|l|}{ Completion of methadone detoxification } \\
\hline Yes & 119 & 81 \\
\hline No & 28 & 19 \\
\hline \multicolumn{3}{|l|}{ Type of discharge } \\
\hline Planned & 62 & 42 \\
\hline Dismissed & 8 & 5 \\
\hline Discharge against medical advice & 74 & 51 \\
\hline Transferred elsewhere & 2 & I \\
\hline
\end{tabular}

I. Data-set incomplete: $n<149$ for many of the patient characteristics. 
methadone detoxification. Overall, $58 \%$ had an unplanned discharge and their median duration of admission was 14 days $(\mathrm{IQR}=10-23)$. The median stay of the $42 \%$ who had a planned discharge was 41 days (IQR=39-42).

Five patients were known to have died prior to follow-up. One hundred and nine $(76 \%)$ of the remaining patients were interviewed. We examined the baseline sociodemographic, drug misuse and treatment adherence characteristics of all patients and found no significant differences between those followed-up and those lost to follow-up. The period from discharge to follow-up ranged from 18 to 42 months, with a median of 29 months. Face-to-face interviews were conducted with all patients apart from five who completed telephone interviews. No patients were in residential treatment at follow-up.

At follow-up, 45 (41\%) reported heroin use and $20(18 \%)$ reported methadone misuse. Overall, $54(50 \%)$ reported misuse of at least one opiate. Sixteen $(15 \%)$ were using heroin daily. Among the 86 patients who completed the methadone detoxification, $46(53 \%)$ reported no recent opiate misuse. Sixty-two $(57 \%)$ were on methadone maintenance treatment at follow-up.

Table 2 indicates the factors associated with the main outcome variable, recent abstinence from all opiate use, both illicit and prescribed. Twenty-three per cent reported opiate abstinence. Only those characteristics that were at least weakly associated with this outcome (OR greater than 2 or less than 0.5 ) are reported. On univariate analysis, abstinence was significantly associated with completion of the in-patient treatment programme, attendance at after-care treatment for at least 6 months following discharge, no previous drug injecting and absence of a family history of substance misuse. Abstinence was not associated with other socio-demographic characteristics, nor was it associated with past psychiatric history, previous addiction treatment, duration of opiate use or quantity of heroin use at baseline. The time interval from discharge to follow-up was not associated with outcome.

On the multivariate analysis, abstinence was significantly associated with completion of the in-patient treatment programme (OR=4.1, 95\% CI 1.4-11.9), persistence with after-care $(\mathrm{OR}=7.6,95 \%$ CI 2.325.3) and absence of a family history of substance misuse $(\mathrm{OR}=3.3,95 \% \mathrm{CI}$ 1.1-9.9).

\section{DISCUSSION}

\section{Admission characteristics and treatment adherence}

The cohort admitted to Cuan Dara was substantially younger and had a shorter history of opiate use than cohorts from

Table 2 Association between pre-admission characteristics and treatment completion with attainment of the goal of abstinence from all opiates (both illicit and prescribed) at 2- to 3-year follow-up among 109 patients admitted to a drug dependency unit in Dublin

\begin{tabular}{|c|c|c|c|c|c|c|c|c|}
\hline \multirow[t]{2}{*}{ Characteristic } & \multirow[t]{2}{*}{$n^{\prime}$} & \multirow{2}{*}{$\begin{array}{c}\text { Not using any } \\
\text { opiates }(n)\end{array}$} & \multicolumn{3}{|c|}{ Univariate analysis } & \multirow[b]{2}{*}{ AOR } & \multicolumn{2}{|c|}{ Multivariate analysis ${ }^{2}$} \\
\hline & & & Odds ratio & $95 \% \mathrm{Cl}$ & $P$ & & $95 \% \mathrm{Cl}$ & $P$ \\
\hline Total & 109 & 25 & & & & & & \\
\hline \multicolumn{9}{|l|}{ Imprisonment } \\
\hline Never in prison & 64 & 19 & 1.0 & & & & & \\
\hline In prison & 43 & 6 & 0.4 & $0.1-I . I$ & 0.06 & & & \\
\hline \multicolumn{9}{|l|}{ Family history } \\
\hline No family history of substance misuse & 43 & 14 & 1.0 & & & 1.0 & & \\
\hline Family history of substance misuse & 66 & II & 0.4 & $0.2-1.0$ & 0.05 & 0.3 & $0.1-0.9$ & 0.04 \\
\hline \multicolumn{9}{|l|}{ Number of previous opiate detoxifications } \\
\hline None & 30 & 9 & 1.0 & & & & & \\
\hline One or more & 76 & 14 & 1.9 & $0.7-5.0$ & 0.19 & & & \\
\hline \multicolumn{9}{|l|}{ History of drug injection } \\
\hline No injecting & 26 & 10 & 1.0 & & & & & \\
\hline Injected previously & 83 & 15 & 0.4 & $0.1-0.9$ & 0.03 & & & \\
\hline \multicolumn{9}{|l|}{ Co-dependence on benzodiazepines } \\
\hline No & 45 & 14 & 1.0 & & & & & \\
\hline Yes & 63 & II & 0.5 & $0.2-1.2$ & 0.10 & & & \\
\hline \multicolumn{9}{|l|}{ Completion of methadone detoxification } \\
\hline Incomplete & 21 & 2 & 1.0 & & & & & \\
\hline Completed & 86 & 22 & 3.3 & $0.70-15.2$ & 0.11 & & & \\
\hline \multicolumn{9}{|l|}{ Type of discharge } \\
\hline Planned & 42 & 16 & 4.2 & I.I-II.I & 0.002 & 4.1 & $1.4-11.9$ & 0.01 \\
\hline Unplanned & 63 & 8 & 1.0 & & & 1.0 & & \\
\hline \multicolumn{9}{|l|}{ After-care } \\
\hline None or less than 6 months & 83 & 14 & 1.0 & & & 1.0 & & \\
\hline Six months or more & 24 & II & 4.2 & $1.6-11.2$ & 0.003 & 7.6 & $2.3-25.3$ & 0.001 \\
\hline
\end{tabular}

AOR, adjusted odds ratio.

I. Data-set incomplete: $n<109$ for many of the patient characteristics.

2. From the logistic regression equation, the Nakelkerke $R^{2}=0.31$. 
other countries (Gossop et al, 1998; Broers et al, 2000; Chutuape et al, 2001; Ghodse et al, 2002). More than $90 \%$ were unemployed but they had relatively stable accommodation, with over half of the group living with parents. Over one-third had a sibling who used opiates and almost one-fifth reported a history of parental alcohol misuse. The rates of completion of the methadone detoxification and of the full treatment programme are equivalent to those in other in-patient settings (Gossop et al, 1986; Ghodse et al, 1987; Polkinghorne et al, 1996; Broers et al, 2000).

\section{Follow-up}

The follow-up rate achieved in this study is equivalent to that in similar studies (Hubbard et al, 1997; Gossop et al, 1999). Nevertheless, loss to follow-up is a concern, as those patients who are difficult to locate may be more likely to be using opiates. The absence of any significant difference between the baseline and treatment adherence characteristics of those followed-up compared with those not located suggests selection bias was not prominent.

The period from discharge to follow-up varied substantially in this study owing to methodological issues already discussed. We found no association between duration of follow-up and abstinence. The NTORS demonstrated that the treatment gains obtained at 1 year remained relatively static at years 2 and 5 (Gossop et al, 2003). Although individual patients may alternate between relapse and abstinence during subsequent years, the proportions of patients moving in each direction tend to cancel each other out beyond the first year after treatment.

\section{Mortality}

The five deaths that occurred in this young cohort are consistent with international mortality rates of 1-2 per 100 person-years (Oppenheimer et al, 1994; Gossop et al, 2002). It should be noted that one of the risks associated with abstinence-orientated treatments is accidental overdose following relapse due to the reduction in opiate tolerance (Strang et al, 2003).

\section{Methadone maintenance treatment}

Over half of the cohort was on methadone maintenance treatment at follow-up. This indicates that many patients relapsed following discharge and subsequently reaccessed treatment. In Switzerland, Broers et al (2000) found that $35 \%$ of those admitted for in-patient opiate detoxification were on methadone maintenance when followed-up after 6 months. Other studies have demonstrated that early relapse is a frequent outcome following in-patient treatment (Chutuape et al, 2001). The fact that opiate dependence frequently follows a chronic relapsing course highlights the need for an accessible and comprehensive range of therapeutic interventions for this patient group.

\section{Drug misuse outcomes}

The NTORS demonstrated a significant decline in heroin misuse among patients offered residential treatment, from $74 \%$ at admission to $49 \%$ at 1 -year follow-up (Gossop et al, 1999). Chutuape et al (2001) and Broers et al (2000) found that about $30 \%$ of patients reported abstinence from heroin 6 months after a brief inpatient opiate detoxification. We found that although $89 \%$ of the patients were admitted with a primary problem of heroin dependence, only $41 \%$ reported recent heroin misuse at follow-up and only $15 \%$ report daily heroin use. Although baseline and follow-up data were obtained using different methodologies, our findings support the view that in-patient treatment is effective in reducing heroin misuse. Among those who completed at least the methadone detoxification phase of treatment, $53 \%$ denied any opiate misuse at followup. Gossop et al (1989) found an almost identical proportion in their 6-month follow-up study.

The reduction in misuse of heroin cannot be entirely attributed to in-patient treatment. Many patients were on methadone maintenance at follow-up and this will also have contributed to the reduced rates of use. While reliance on self-report of substance misuse at follow-up may be considered a weakness of this study design, similar studies have found that self-report correlates highly with results of urine testing (Gossop et al, 1997; Darke, 1998).

\section{Achievement of abstinence}

At follow-up, $23 \%$ of participants had achieved their initial treatment goal of abstinence from opiates without the assistance of methadone maintenance. Most studies examining outcome following in-patient treatment report proportions using heroin before and after treatment, without making it clear that those who are abstaining from heroin at follow-up are not receiving methadone maintenance treatment (Gossop et al, 1989, 1999; Broers et al, 2000; Chutuape et al, 2001). In seeking to clarify this important issue, we found that almost one in four were genuinely abstinent after an average of 2.5 years. This should be a source of optimism to patients, to commissioners of addiction services and to those who deliver similar services. It should be noted, however, that abstinence during the month prior to follow-up interview does not imply abstinence throughout the follow-up period.

In this era of harm reduction, abstinence has become a secondary goal of treatment services. Dublin has embraced the principles of harm reduction, and a well-developed treatment infrastructure existed at the time of this study (Farrell et al, 1999). This included relatively easy access to methadone maintenance treatment. Reservations have long been expressed that improved access to methadone maintenance might reduce the possibility of drug misusers attaining abstinence (Bratter \& Pennacchia, 1978; Gerlach \& Schneider, 1991). This study indicates that abstinence remains an attainable goal and confirms our first hypothesis.

Abstinent patients were more likely to have completed the in-patient treatment programme and more likely to have attended after-care treatment for at least 6 months. The DATOS failed to demonstrate that better outcome was predicted by a longer stay in short-term in-patient treatment programmes such as that delivered in this study (Hubbard et al, 1997). This may be due to differences in treatment delivery in the USA and substantial differences in the patient population: the vast majority of patients in DATOS presented with cocaine dependence. There is much other research consistent with our findings that significant improvement in outcome is associated with better treatment adherence and with transfer to long-term outpatient after-care following in-patient addiction treatment (van de Velde et al, 1998; Gossop et al, 1999; Chutuape et al, 2001; Ghodse et al, 2002). In-patient treatment is an expensive and limited resource. In order to maximise the health gain that such services can deliver we need to identify more effectively those patients who are most likely to persist with treatment. There 
is also a need to improve our understanding of the factors within different in-patient and after-care programmes that facilitate patient attendance. Finally, there is a need to develop imaginative measures that can actively enhance treatment adherence at all stages of the treatment process (Horwitz \& Horwitz, 1993; Giuffrida \& Torgenson, 1997).

The finding that a family history of substance misuse was associated with a significant reduction in the likelihood of abstinence was unexpected. There are a number of possible explanations for this. Environmental explanations seem most plausible. Two-thirds of those who reported a family history of substance misuse identified a sibling who was misusing opiates. Returning home to an environment with an opiate-using sibling may have made heroin access easier and promoted relapse (Maisto et al, 2001). There is also a possible contribution of genetic influences. However, it may simply represent a chance finding as a result of a type 2 statistical error in view of the large number of statistical tests conducted in this study.

In common with many other addiction treatment studies, we found that patient pre-admission characteristics account for a very small proportion of the variance in outcome. Consequently, there is minimal evidence to support their use in prioritising access to in-patient treatment.

This study suggests that in-patient treatment can be effective for opiatedependent patients, particularly when the patient completes treatment and proceeds to access after-care. In addition, evidence from the USA indicates that it can also be a cost-effective option compared with outpatient treatments (French et al, 2000). Inpatient addiction services must strive to develop strategies to improve rates of programme completion. Commissioners of addiction services should ensure after-care is available and drug dependency units should actively facilitate patient transfer to such services following discharge.

\section{ACKNOWLEDGEMENTS}

We thank Duncan Stewart and John Marsden for their advice on adaptation of the Maudsley Addiction Profile for use in this study. We also thank Alan Kelly for his statistical advice. The team of outreach workers demonstrated great diligence and determination in locating so many patients for follow-up interview.

\section{CLINICAL IMPLICATIONS}

- Almost one in four patients report abstinence from opiates, without the assistance of methadone maintenance, 2-3 years after in-patient treatment of opiate dependence.

- Abstinence is associated with completion of the in-patient programme and attendance at after-care. Consequently, the health gain from the in-patient treatment may be enhanced by improving rates of programme completion and ensuring easy access to after-care.

- Pre-treatment socio-demographic and drug misuse characteristics are poor predictors of outcome and should not be used for selection of patients for abstinence-orientated in-patient treatment.

\section{LIMITATIONS}

- Different methodologies were used to measure substance misuse characteristics at baseline and follow-up.

- The time from discharge to follow-up varied substantially (from 18 months to 42 months).

- In common with most studies of outcome following addiction treatment, the failure to include a control group makes it impossible to determine an effect size.

BOBBY P. SMYTH, MRCPsych, AIDS/Drugs Service, Cherry Orchard Hospital, Dublin I0; JOE BARRY, MD, Department of Public Health and Primary Care, Trinity College, Dublin; ALISON LANE, MSc, St Patrick's Hospital, Dublin 8; MARY COTTER, RGN RPN, AIDS/Drugs Service, Cherry Orchard Hospital, Dublin I0; MARY O'NEILL, RGN, Baggot Street Clinic, Dublin 4; CAROLINE QUINN, RGN, EAMON KEENAN, MRCPsych, AIDS/Drugs Service, Cherry Orchard Hospital, Dublin I0, Ireland

Correspondence: Dr Bobby P. Smyth, Department of Public Health and Primary Care, Adelaide and Meath Hospital, Tallaght, Dublin 24, Ireland. E-mail: bobby.smyth@swahb.ie

(First received 3 March 2003, final revision 2 February 2004, accepted 14 February 2004)

\section{REFERENCES}

Bratter, T. E. \& Pennacchia, M. C. (1978) The negative self-fulfilling prophecy of methadone maintenance. Corrective and Social Psychiatry and Journal of Behavior Technology, Methods and Therapy, 24, I-5.

Broers, B., Giner, F., Dumont, P., et al (2000) Inpatient opiate detoxification in Geneva: follow-up at I and 6 months. Drug and Alcohol Dependence, 58, 85-92.

Butler, S. (2002) The making of the methadone protocol: the Irish system? Drugs: Education, Prevention and Policy, 9, 31I-324.

Chutuape, M. A., Jasinski, D. R., Fingerhood, M. I., et al (200I) One-, three-, and six-month outcomes after brief inpatient opioid detoxification. American Journal of Drug and Alcohol Abuse, 27, 19-44.

Darke, S. (1998) Self-report among injecting drug users: a review. Drug and Alcohol Dependence, 5I, 253263.
Farrell, M., Howes, S., Verster, A., et al (1999) Reviewing Current Practice in Drug Substitution Treatment in Europe. Project no. CT.98DR 10. Lisbon: European Monitoring Centre for Drugs and Alcohol Addiction.

French, M. T., Salome, H. J., Krupski, A., et al (2000) Benefit-cost analysis of residential and outpatient addiction treatment in the State of Washington. Evaluation Review, 24, 609-634.

Gerlach, R. \& Schneider, W. (1991) Abstinence and acceptance? The problematic relationship between the German abstinence paradigm, low-threshold orientated drug work, and methadone. Drug and Alcohol Review, I0, $417-421$.

Ghodse, A. H., London, M., Bewley, T. H., et al (1987) In-patient treatment for drug abuse. British journal of Psychiatry, I5I, 72-75.

Ghodse, A. H., Reynolds, M., Baldacchino, A. M., et al (2002) Treating an opiate-dependent inpatient population: a one-year follow-up study of treatment completers and noncompleters. Addictive Behaviors, 27, 765-778. 
Giuffrida, A. \& Torgenson, D. J. (1997) Should we pay the patient? Review of financial incentives to enhance patient compliance. BMJ, 315, 703-707.

Gossop, M., Johns, A. \& Green, L. (1986) Opiate withdrawal: inpatient versus outpatient programmes and preferred versus random assignment to treatment. BMJ, 293, 103-104.

Gossop, M., Green, L., Phillips, G., et al (1989) Lapse, relapse and survival among opiate addicts after treatment. A prospective follow-up study. British Journal of Psychiatry, I54, 348-353.

Gossop, M., Marsden, J., Stewart, D., et al (1997) The National Treatment Outcome Research Study in the United Kingdom: six month follow-up outcomes. Psychology of Addictive Behaviors, II, 324-337.

Gossop, M., Marsden, J., Stewart, D., et al (1998) Substance use, health and social problems of service users at 54 drug treatment agencies. Intake data from the National Treatment Outcome Research Study British Journal of Psychiatry, 173, 166-171.

Gossop, M., Marsden, J., Stewart, D., et al (1999)

Treatment retention and I year outcomes for residentia programmes in England. Drug and Alcohol Dependence, 57, 89-98.
Gossop, M., Stewart, D., Treacy, S., et al (2002) A prospective study of mortality among drug misusers during a 4-year period after seeking treatment. Addiction, 97, 39-47.

Gossop, M., Marsden, J., Stewart, D., et al (2003) The National Treatment Outcome Research Study (NTORS): 4-5 year follow-up results. Addiction, 98 291-303.

Horwitz, R. I. \& Horwitz, S. M. (1993) Adherence to treatment and health outcomes. Archives of Internal Medicine, 153, 1863-1868.

Hubbard, R. L., Craddock, S. G., Flynn, P. M., et al (1997) Overview of I-year follow-up outcomes in the Drug Abuse Treatment Outcome Study (DATOS).

Psychology of Addictive Behaviors, II, 261-278.

Maisto, S., Pollock, N., Lynch, K., et al (200I) Course of functioning in adolescents I year after alcohol and other drug treatment. Psychology of Addictive Behaviours, I5, 68-76.

Marsden, J., Gossop, M., Stewart, D., et al (1998) Th Maudsley Addiction Profile (MAP): a brief instrument for assessing treatment outcome. Addiction, 93, 18571868.
Oppenheimer, E., Tobutt, C., Taylor, C., et al (1994) Death and survival in a cohort of heroin addicts from London clinics: a 22-year follow-up. Addiction, 89, 1299 1308.

Polkinghorne, J., Farrell, M., Fry, M., et al (1996) The Task Force to Review Services for Drug Misusers: Report of an Independent Review of Drug Treatment Services in England. London: Department of Health.

Smyth, B. P., O'Brien, M. \& Barry, J. (2000) Trends in treated opiate misuse in Dublin: the emergence of chasing the dragon. Addiction, 95, 1217-1223.

Strang, J., McCambridge, J., Best, D., et al (2003) Loss of tolerance and overdose mortality after inpatient opiate detoxification: follow up study. British Medical Journal, 326, 959-960.

van de Velde, J. C., Schaap, G. E. \& Land, H. (1998) Follow-up at a Dutch addiction hospital and the effectiveness of therapeutic community treatment. Substance Use and Misuse, 33, 1611-1627.

World Health Organization (1992) Classification of Mental and Behavioural Disorders. Geneva: WHO. 